Article

\title{
Numerical Study for Magnetohydrodynamic Flow of Nanofluid Due to a Rotating Disk with Binary Chemical Reaction and Arrhenius Activation Energy
}

\author{
Mir Asma ${ }^{1}$, W.A.M. Othman ${ }^{1, *}$, Taseer Muhammad ${ }^{2}$, Fouad Mallawi ${ }^{3}$ and B.R. Wong ${ }^{1}$ \\ 1 Institute of Mathematical Sciences, Faculty of Science, University of Malaya, Kuala Lumpur 50603, Malaysia; \\ miraszaka@gmail.com (M.A.); bernardr@um.edu.my (B.R.W.) \\ 2 Department of Mathematics, Government College Women University, Sialkot 51310, Pakistan; \\ taseer_qau@yahoo.com \\ 3 Department of Mathematics, Faculty of Science, King Abdulaziz University, Jeddah 21589, Saudi Arabia; \\ fmallawi@kau.edu.sa \\ * Correspondence: wanainun@um.edu.my
}

Received: 5 August 2019; Accepted: 1 October 2019; Published: 14 October 2019

\begin{abstract}
This article examines magnetohydrodynamic 3D nanofluid flow due to a rotating disk subject to Arrhenius activation energy and heat generation/absorption. Flow is created due to a rotating disk. Velocity, temperature and concentration slips at the surface of the rotating disk are considered. Effects of thermophoresis and Brownian motion are also accounted. The nonlinear expressions have been deduced by transformation procedure. Shooting technique is used to construct the numerical solution of governing system. Plots are organized just to investigate how velocities, temperature and concentration are influenced by various emerging flow parameters. Skin-friction Local Nusselt and Sherwood numbers are also plotted and analyzed. In addition, a symmetry is noticed for both components of velocity when Hartman number enhances.
\end{abstract}

Keywords: rotating disk; Arrhenius activation energy; nanoparticles; binary chemical reaction; MHD; heat generation/absorption; slip effects; numerical solution

\section{Introduction}

Low thermal efficiency of working liquids is a principle issue for a few heat transport components in the designing of applications. Therefore a few scientists are occupied with the request to build up an imaginative route for development of thermal productivity of working liquids. Different components have been proposed by specialists to improve the thermal productivity of liquids. Therefore, the inclusion of nanomaterial in working liquid termed as nanofluid is very alluring component. Recent examinations on nanofluid have uncovered that working fluid has various highlights with nanomaterial blend. This is on the grounds that the thermal proficiency of working fluid is weaker than nanofluid thermal productivity. Nanofluid is a recently perceived group of liquids containing working liquid with the particles of nano measure. Such nanomaterials are employed in MHD control generators, oil stores, cooling of atomic reactors, malignancy treatment, vehicle transformer and several others [1-5]. The word nanofluid was first used by Choi [6] to explain the thermal conductivity of ordinary liquids. From the perspective of exploring how thermal conductivity is expanded, various examinations are introduced by him. Further attempts on nanofluids can be cited through investigations [7-20].

Analysts are presently much occupied by exploring fluid flow via rotating disk. It is because of its numerous applications in various fields of technology, for example, design branches and aeronautical science such as gem development forms, electronic gadgets, pivoting hardware, PC stockpiling gadgets, 
thermal power producing systems, gas turbine rotors, air cleaning machines, restorative gear and several others [21-23]. Von Karman [24] provided pioneering work with fluid flow via rotating disk. He examined the subsequent issue diagnostically. Cochran [25] proved an asymptotic answer for the von Karman issue. Millsaps and Pohlhansen [26] examined the issue of heat transfer for the isothermal plate. Ackroyd [27] thought about suction/infusion impacts in the Von Karman issue and he created a solution by exponentially rotting coefficients. Miclavcic and Wang [28] broadened the Von Karman issue for circumstances where a rotating disk concedes partial slip attributes. Attia [29] examined fluid flow because of a rotating disk inundated in a permeable space by using the Wrench Nicolson technique. Flow of viscous fluid by permeable disk subject to pivoting casing and heat/mass exchange was analyzed by Turkyilmazoglu and Senel [30]. They processed numeric consequences of governing flow issue. Rashidi et al. [31] analyzed impacts of entropy generation in MHD flow of viscous fluid by rotating disk. Hatami et al. [32] talked about laminar flow of nanofluids instigated by turning contracting disk. Mustafa et al. [33] investigated the flow of nanoliquid initiated by a rotating disk. They inferred that uniform extension of a disk is a significant factor for decreasing boundary-layer thickness. Sheikholeslami et al. [34] accounted for nanofluid flow incited by a slanted rotating plate. Hayat et al. [35] examined flow by a rotating disk through a magnetic field, slip and nanoparticle impact. Flow of MHD nanoliquid by rotating disk subject to slip was explored by Mustafa [36]. Darcy Forchheimer flow of carbon nanotubes incited by a rotating disk was examined by Hayat et al. [37]. Further relevant attempts regarding rotating disks can be seen through investigations [38-40].

Propelled by the above articles, the goal here is to look at the combined impacts of Arrhenius activation energy and binary chemical reactions in hydromagnetic 3D flow of nanofluid by rotating disk with heat generation/absorption and slip impacts. The random movement and thermophoretic dispersion phenomena occur because of the nanoparticles. Velocity, thermal and concentration slips are considered. The governing system is solved numerically by shooting procedure. Velocities, temperature, concentration and local Sherwood and Nusselt numbers are additionally discussed through curves.

\section{Statement}

We analyze MHD steady three-dimensional flow of nanoliquid by rotating disk with thermal generation/absorption and slip impacts. Arrhenius activation energy and binary chemical reaction impacts are additionally present. Disk at $z=0$ pivots with constant angular velocity $\Omega$. Brownian dispersion and thermophoretic impacts are also present. Magnetic field of strength $B_{0}$ acts in $z$-direction (see Figure 1). The velocity components $(u, v, w)$ are in the directions of expanding $(r, \varphi, z)$ respectively. Resulting boundary-layer expressions are

$$
\begin{gathered}
\frac{\partial u}{\partial r}+\frac{u}{r}+\frac{\partial w}{\partial z}=0 \\
u \frac{\partial u}{\partial r}-\frac{v^{2}}{r}+w \frac{\partial u}{\partial z}=v\left(\frac{\partial^{2} u}{\partial r^{2}}+\frac{1}{r} \frac{\partial u}{\partial r}-\frac{u}{r^{2}}+\frac{\partial^{2} u}{\partial z^{2}}\right)-\frac{\sigma B_{0}^{2}}{\rho_{f}} u \\
u \frac{\partial v}{\partial r}+\frac{u v}{r}+w \frac{\partial v}{\partial z}=v\left(\frac{\partial^{2} v}{\partial r^{2}}+\frac{1}{r} \frac{\partial v}{\partial r}-\frac{v}{r^{2}}+\frac{\partial^{2} v}{\partial z^{2}}\right)-\frac{\sigma B_{0}^{2}}{\rho_{f}} v \\
u \frac{\partial w}{\partial r}+w \frac{\partial w}{\partial z}=v\left(\frac{\partial^{2} w}{\partial r^{2}}+\frac{1}{r} \frac{\partial w}{\partial r}+\frac{\partial^{2} w}{\partial z^{2}}\right) \\
u \frac{\partial T}{\partial r}+w \frac{\partial T}{\partial z}=\alpha_{m}\left(\frac{\partial^{2} T}{\partial r^{2}}+\frac{1}{r} \frac{\partial T}{\partial r}+\frac{\partial^{2} T}{\partial z^{2}}\right)+\frac{Q}{(\rho c)_{f}}\left(T-T_{\infty}\right) \\
+\frac{(\rho c)_{p}}{(\rho c)_{f}}\left(D_{B}\left(\frac{\partial T}{\partial r} \frac{\partial C}{\partial r}+\frac{\partial T}{\partial z} \frac{\partial C}{\partial z}\right)+\frac{D_{T}}{T_{\infty}}\left(\left(\frac{\partial T}{\partial r}\right)^{2}+\left(\frac{\partial T}{\partial z}\right)^{2}\right)\right)
\end{gathered}
$$




$$
\begin{aligned}
u \frac{\partial C}{\partial r}+w \frac{\partial C}{\partial z}= & D_{B}\left(\frac{\partial^{2} C}{\partial r^{2}}+\frac{1}{r} \frac{\partial C}{\partial r}+\frac{\partial^{2} C}{\partial z^{2}}\right) \\
& +\frac{D_{T}}{T_{\infty}}\left(\frac{\partial^{2} T}{\partial r^{2}}+\frac{1}{r} \frac{\partial T}{\partial r}+\frac{\partial^{2} T}{\partial z^{2}}\right)-k_{r}^{2}\left(C-C_{\infty}\right)\left(\frac{T}{T_{\infty}}\right)^{n} \exp \left(-\frac{E_{a}}{\kappa T}\right), \\
u=L_{1} \frac{\partial u}{\partial z}, v= & r \Omega+L_{1} \frac{\partial v}{\partial z}, w=0, T=T_{w}+L_{2} \frac{\partial T}{\partial z}, C=C_{w}+L_{3} \frac{\partial C}{\partial z} \text { at } z=0, \\
u & \rightarrow 0, \quad v \rightarrow 0, \quad T \rightarrow T_{\infty}, C \rightarrow C_{\infty} \text { when } z \rightarrow \infty .
\end{aligned}
$$

Here $u, v$ and $w$ represent velocities in directions of $r, \varphi$ and $z$ while $\rho_{f}, v\left(=\mu / \rho_{f}\right)$ and $\mu$ show density, kinematic and dynamic viscosities, respectively, $L_{1}$ the velocity slip factor, $(\rho c)_{p}$ the effective heat capacity of nanoparticles, $E_{a}$ the activation energy, $(\rho c)_{f}$ heat capacity of liquid, $L_{2}$ the thermal slip factor, $\sigma$ the electrical conductivity, $C$ the concentration, $n$ the fitted rate constant, $C_{\infty}$ the ambient concentration, $D_{T}$ the thermophoretic factor, $\alpha_{m}=k /(\rho c)_{f}$ and $k$ the thermal diffusivity and thermal conductivity respectively, $T$ the fluid temperature, $k_{r}$ the reaction rate, $D_{B}$ the Brownian factor, $L_{3}$ the concentration slip factor, $Q$ the heat generation/absorption factor, $\kappa$ the Boltzmann constant and $T_{\infty}$ the ambient temperature. Selecting

$$
\left.\begin{array}{c}
u=r \Omega f^{\prime}(\zeta), w=-(2 \Omega v)^{1 / 2} f(\zeta), v=r \Omega g(\zeta), \\
\phi(\zeta)=\frac{C-C_{\infty}}{C_{w}-C_{\infty}}, \zeta=\left(\frac{2 \Omega}{v}\right)^{1 / 2} z, \theta(\zeta)=\frac{T-T_{\infty}}{T_{w}-T_{\infty}} .
\end{array}\right\}
$$

Continuity Equation (1) is trivially verified while Equations (2)-(8) yield

$$
\begin{gathered}
2 f^{\prime \prime \prime}+2 f f^{\prime \prime}-f^{\prime 2}+g^{2}-(H a)^{2} f^{\prime}=0, \\
2 g^{\prime \prime}+2 f g^{\prime}-2 f^{\prime} g-(H a)^{2} g=0, \\
\frac{1}{\operatorname{Pr}} \theta^{\prime \prime}+f \theta^{\prime}+N_{b} \theta^{\prime} \phi^{\prime}+N_{t} \theta^{\prime 2}+\delta_{1} \theta=0, \\
\frac{1}{S c} \phi^{\prime \prime}+f \phi^{\prime}+\frac{1}{S c} \frac{N_{t}}{N_{b}} \theta^{\prime \prime}-\sigma(1+\delta \theta)^{n} \phi \exp \left(-\frac{E}{1+\delta \theta}\right)=0, \\
f(0)=0, f^{\prime}(0)=\alpha f^{\prime \prime}(0), g(0)=1+\alpha g^{\prime}(0), \theta(0)=1+\beta \theta^{\prime}(0), \phi(0)=1+\gamma \phi^{\prime}(0), \\
f^{\prime}(\infty) \rightarrow 0, g(\infty) \rightarrow 0, \theta(\infty) \rightarrow 0, \phi(\infty) \rightarrow 0 .
\end{gathered}
$$

Here $N_{t}$ stands for the thermophoresis parameter, $\alpha$ for velocity slip parameter, $\mathrm{Ha}$ for Hartman number, $\sigma$ for chemical reaction parameter, $N_{b}$ for Brownian parameter, $\beta$ for thermal slip parameter, $\delta$ for temperature difference parameter, Pr for Prandtl number, $\gamma$ for concentration slip parameter, $\delta_{1}$ for heat absorption/generation parameter, $S c$ for Schmidt number and $E$ for nondimensional activation energy. Nondimensional variables are defined by

$$
\left.\begin{array}{c}
(H a)^{2}=\frac{\sigma B_{0}^{2}}{\Omega \rho_{f}}, \operatorname{Pr}=\frac{v}{\alpha_{m}}, \alpha=L_{1} \sqrt{\frac{2 \Omega}{v}}, \gamma=L_{3} \sqrt{\frac{2 \Omega}{v}}, \\
N_{t}=\frac{(\rho c)_{p} D_{T}\left(T_{w}-T_{\infty}\right)}{(\rho c)_{f} v T_{\infty}}, S c=\frac{v}{D_{B}}, N_{b}=\frac{(\rho c)_{p} D_{B}\left(C_{w}-C_{\infty}\right)}{(\rho c)_{f} v}, \delta_{1}=\frac{Q}{2 \Omega(\rho c)_{f}}, \\
\beta=L_{2} \sqrt{\frac{2 \Omega}{v}}, \sigma=\frac{k_{r}^{2}}{\Omega}, \delta=\frac{T_{f}-T_{\infty}}{T_{\infty}}, E=\frac{E_{a}}{\kappa T_{\infty}} .
\end{array}\right\}
$$

The coefficients of skin-friction and local Nusselt and Sherwood expressions are

$$
\left.\begin{array}{c}
\operatorname{Re}_{r}^{1 / 2} C_{f}=f^{\prime \prime}(0), \operatorname{Re}_{r}^{1 / 2} C_{g}=g^{\prime}(0), \\
\operatorname{Re}_{r}^{-1 / 2} N u=-\theta^{\prime}(0), \operatorname{Re}_{r}^{-1 / 2} S h=-\phi^{\prime}(0)
\end{array}\right\}
$$

where $\operatorname{Re}_{r}=2(\Omega r) r / v$ represents the local rotational Reynolds number. 


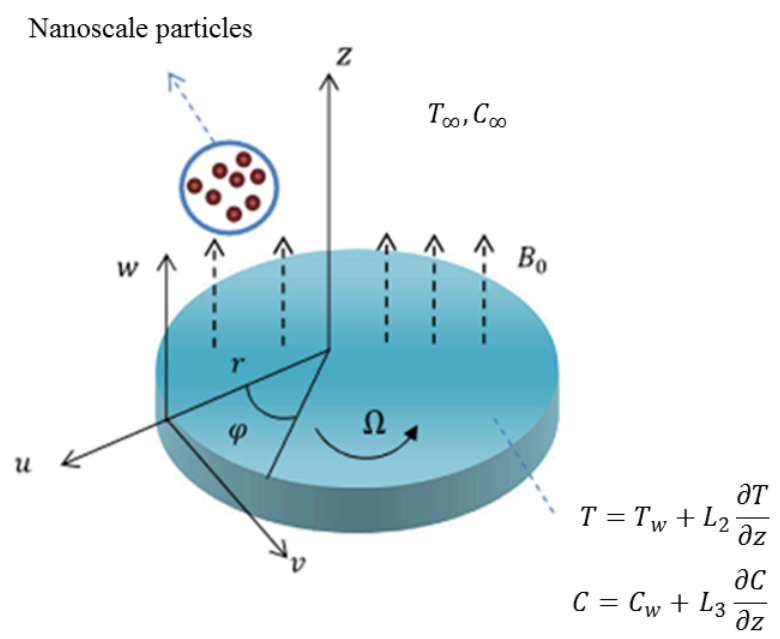

Figure 1. Flow configuration.

\section{Solution Methodology}

By using appropriate boundary conditions on a system of equations, a numerical solution is provided considering NDSolve in Mathematica. Shooting technique is used via NDSolve. This technique is very helpful in the case of small step-sizes featuring negligible error. Consequently, both $r$ and $z$ varied uniformly by a step-size of 0.01 .

\section{Results and Discussion}

This segment outlines the commitment of various relevant parameters including Prandtl number $\operatorname{Pr}$, Hartman number $H a$, thermophoresis parameter $N_{t}$, chemical reaction parameter $\sigma$, velocity slip parameter $\alpha$, Schmidt number $S c$, temperature difference parameter $\delta$, Brownian parameter $N_{b}$, thermal slip parameter $\beta$, activation energy $E$, heat generation/absorption parameter $\delta_{1}$, concentration slip parameter $\gamma$ on velocities $f^{\prime}(\zeta)$ and $g(\zeta)$, concentration $\phi(\zeta)$ and temperature $\theta(\zeta)$ distributions. Figure 2 demonstrates the variety in velocity field $f^{\prime}(\zeta)$ for shifting Hartman parameter Ha. An addition in Hartman parameter Ha relates to bringing down velocity field $f^{\prime}(\zeta)$. Here $\mathrm{Ha}=0$ yields hydromagnetic flow circumstance and $\mathrm{Ha}=0$ speaks to hydro-dynamic flow case. Figure 3 portrays adjustment in velocity field $f^{\prime}(\zeta)$ for differing estimations of velocity slip parameter $\alpha$. Velocity field and related layer are diminished for higher $\alpha$. Figure 4 shows adjustment in velocity field $g(\zeta)$ for fluctuating Hartman parameter Ha. Here we examined that velocity field diminishes when Hartman parameter Ha increments. Figure 5 is portrayed to look at that how velocity field $g(\zeta)$ is influenced with variety of velocity slip $\alpha$. For increasing estimations of $\alpha$, velocity field $g(\zeta)$ indicates diminishing pattern. Figure 6 showcases the impact of Hartman parameter Ha on temperature $\theta(\zeta)$. Obviously, temperature and the related thermal layer are upgraded for increasing Ha. Effect of thermal slip $\beta$ on temperature dissemination $\theta(\zeta)$ is delineated in Figure 7. Improvement in $\beta$ depicts diminishing conduct for $\theta(\zeta)$ and the related thermal layer. Figure 8 shows how heat generation/absorption number $\delta_{1}$ influences temperature dispersion $\theta(\zeta)$. Here $\delta_{1}>0$ portrays heat generation and $\delta_{1}<0$ for heat absorption. Both temperature $\theta(\zeta)$ and thermal layer are upgraded for increasing $\delta_{1}$. Figure 9 introduces a variety in temperature field $\theta(\zeta)$ for differing Prandtl parameter Pr. Here $\theta(\zeta)$ is diminished through Pr. Proportion of momentum diffusivity to thermal diffusivity is termed as Prandtl parameter Pr. Higher estimations of Pr yield more fragile thermal diffusivity which compares to a reduction in thermal layer. Effect of $N_{t}$ on temperature profile $\theta(\zeta)$ is depicted in Figure 10. Addition in $N_{t}$ relates to stronger temperature field $\theta(\zeta)$ and more thermal layer. Figure 11 delineates variety in temperature field $\theta(\zeta)$ for unmistakable estimations of Brownian movement $N_{b}$. Physically, a sporadic movement of nanoparticles improves by expanding Brownian movement $N_{b}$ because of which impact of particles happens. As a result, dynamic vitality is changed into warmth 
vitality which shows an upgrade in temperature profile and the related layer. Figure 12 demonstrates that how Hartman parameter Ha influences concentration $\phi(\zeta)$. By expanding Hartman parameter $\mathrm{Ha}$, both concentration and concentration layers are improved. Figure 13 shows that concentration dispersion $\phi(\zeta)$ is weaker for bigger concentration slip. From Figure 14, we saw that bigger Schmidt parameter Sc demonstrates a rot in concentration field $\phi(\zeta)$. Schmidt parameter is conversely relative to Brownian diffusivity. Increasing Schmidt parameter Sc yields a more fragile Brownian diffusivity. This more fragile Brownian diffusivity prompts lower concentration field $\phi(\zeta)$. Figure 15 demonstrates that how thermophoresis $N_{t}$ influences concentration profile $\phi(\zeta)$. By improving thermophoresis parameter $N_{t}$, the concentration field $\phi(\zeta)$ and related layer are expanded. Figure 16 portrays effect of Brownian movement $N_{b}$ on concentration $\phi(\zeta)$. It is obviously observed that a more fragile concentration $\phi(\zeta)$ is produced by using higher Brownian movement parameter $N_{b}$. Figure 17 explains the impact of nondimensional activation energy $E$ on concentration $\phi(\zeta)$. An improvement in activation energy $E$ rots altered Arrhenius work $\left(\frac{T}{T_{\infty}}\right)^{n} \exp \left(-\frac{E_{a}}{\kappa T}\right)$. This inevitably builds up the generative synthetic response because of which concentration $\phi(\zeta)$ upgrades. Figure 18 introduces an improvement in compound response parameter $\sigma$ shows a rot in concentration $\phi(\zeta)$ and its related layer. Figure 19 explains the impact of $\delta$ on $\phi(\zeta)$. Here $\phi(\zeta)$ is seen as a diminishing capacity of $\delta$. Figure 20 depicts the concentration $\phi(\zeta)$ for evolving $n$. By improving $n$, infiltration profundity of $\phi(\zeta)$ closures become slenderer. Figures 21 and 22 display the effects of $N_{t}$ and $N_{b}$ on $\operatorname{Re}_{r}^{-1 / 2} N u$. From these figures, it has been noticed that $\operatorname{Re}_{r}^{-1 / 2} \mathrm{Nu}$ reduces for higher $N_{t}$ and $N_{b}$. Features of $N_{t}$ and $N_{b}$ on $\operatorname{Re}_{r}^{-1 / 2} S h$ are disclosed through Figures 23 and 24. Interestingly, $\operatorname{Re}_{r}^{-1 / 2} S h$ is an increasing function of $N_{t}$ while it is a decreasing function of $N_{b}$.

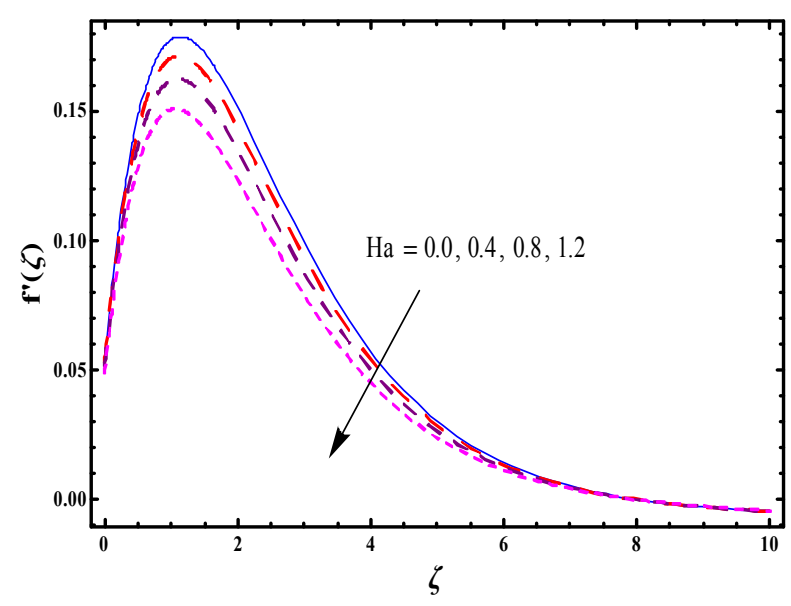

Figure 2. Sketch of $f^{\prime}(\zeta)$ for $H a$.

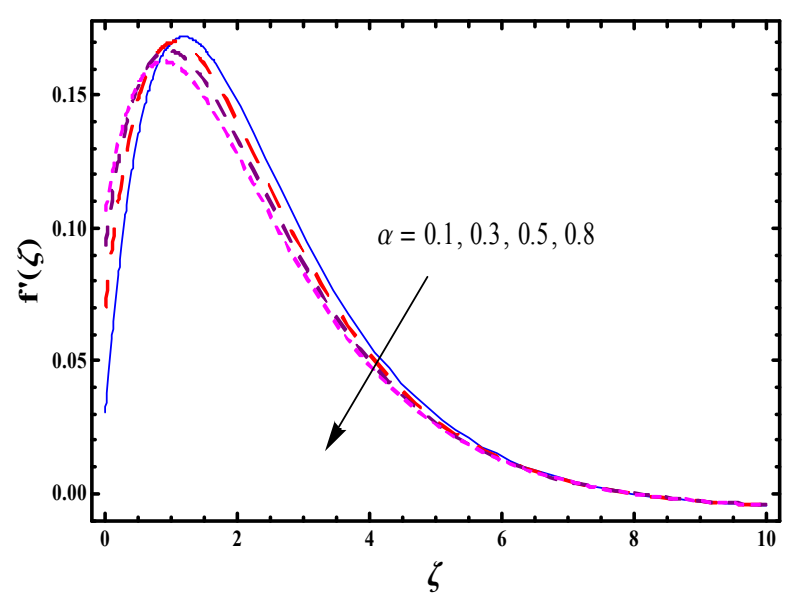

Figure 3. Sketch of $f^{\prime}(\zeta)$ for $\alpha$. 


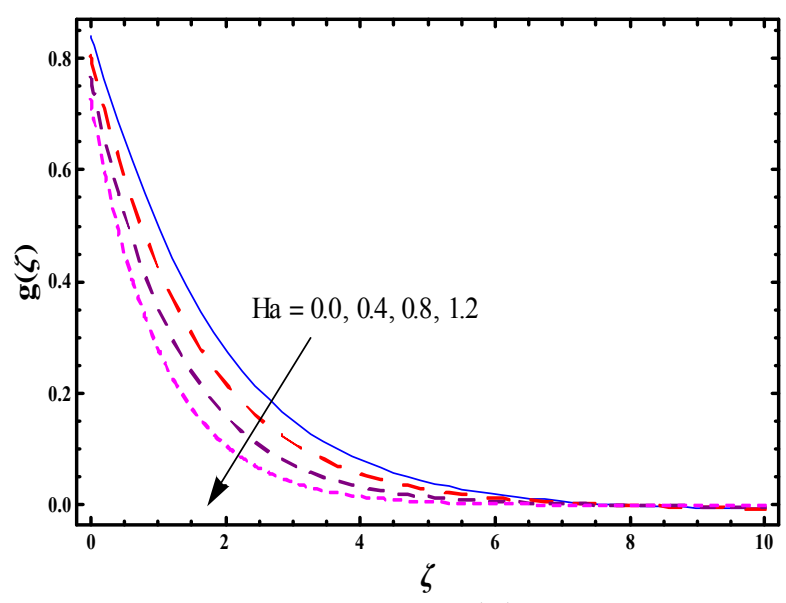

Figure 4. Sketch of $g(\zeta)$ for $H a$.

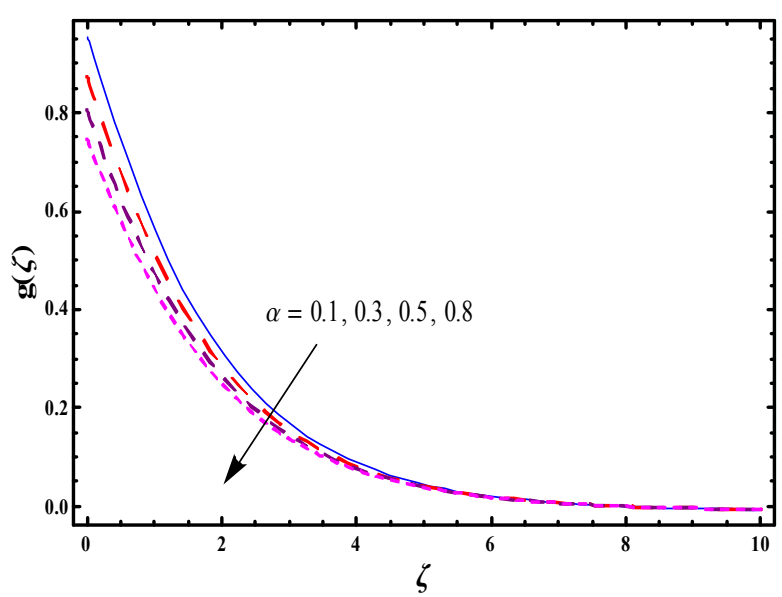

Figure 5. Sketch of $g(\zeta)$ for $\alpha$.

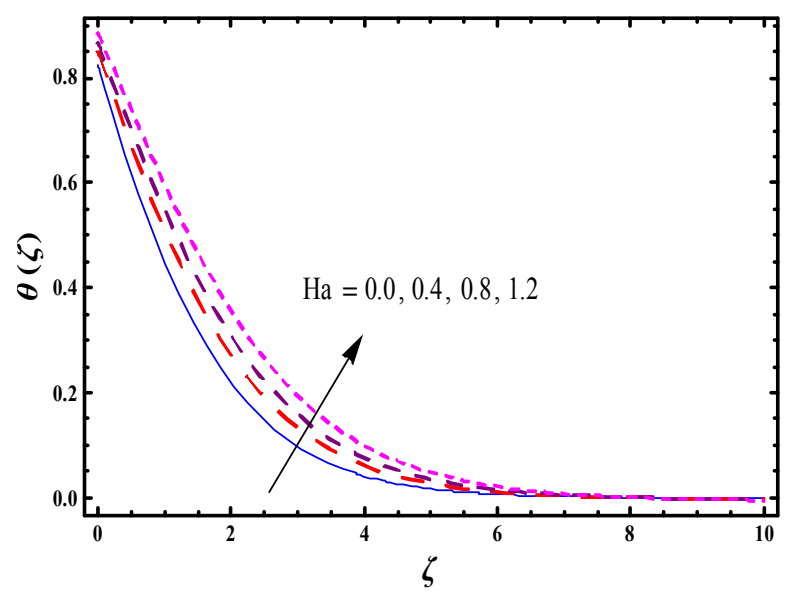

Figure 6. Sketch of $\theta(\zeta)$ for $H a$. 


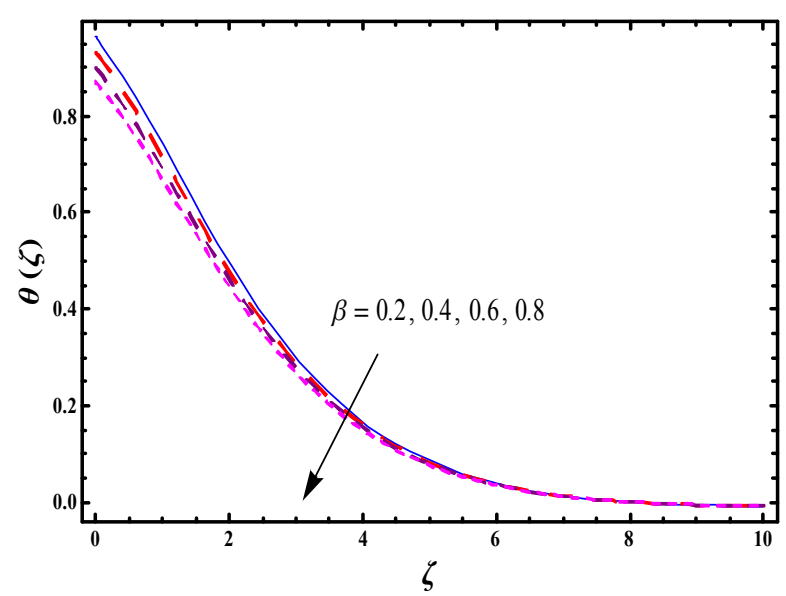

Figure 7. Sketch of $\theta(\zeta)$ for $\beta$.

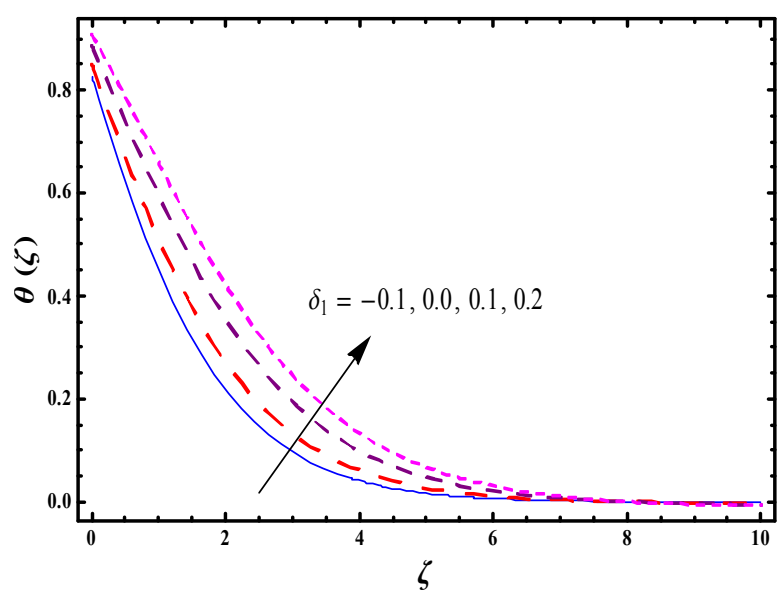

Figure 8. Sketch of $\theta(\zeta)$ for $\delta_{1}$.

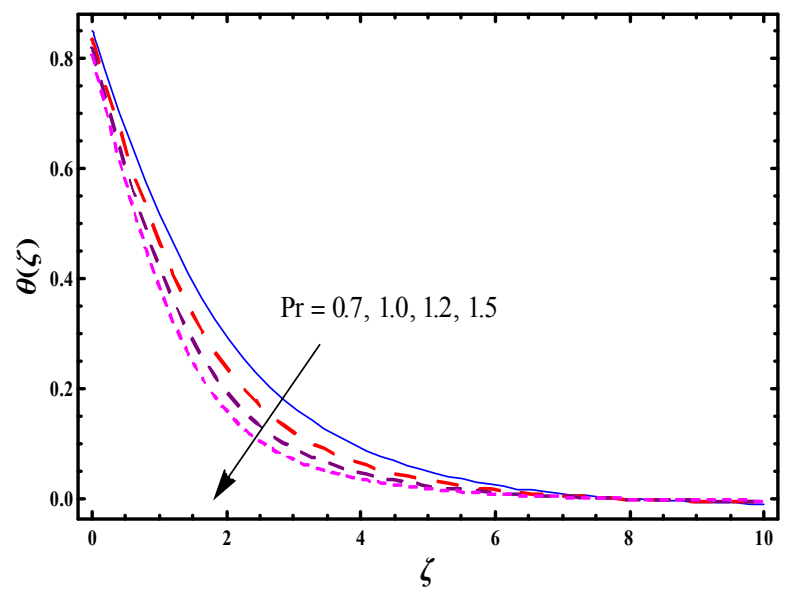

Figure 9. Sketch of $\theta(\zeta)$ for Pr. 


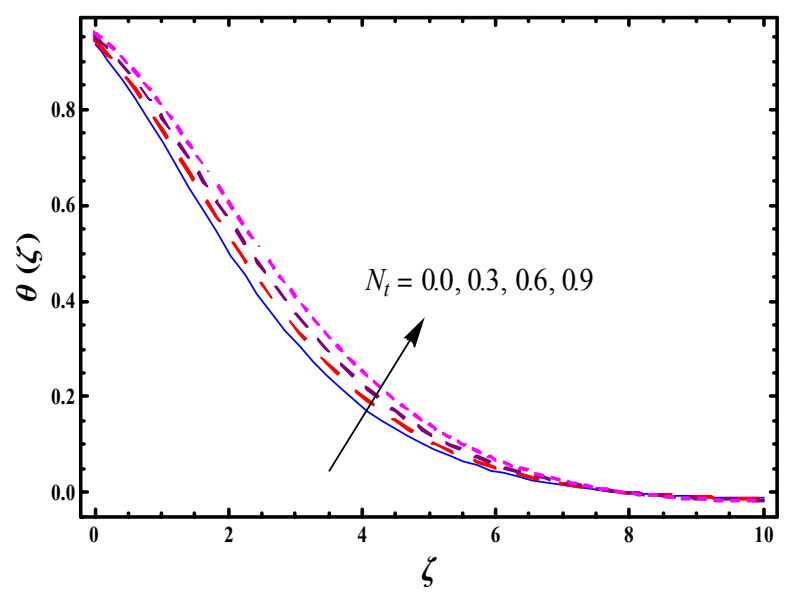

Figure 10. Sketch of $\theta(\zeta)$ for $N_{t}$.

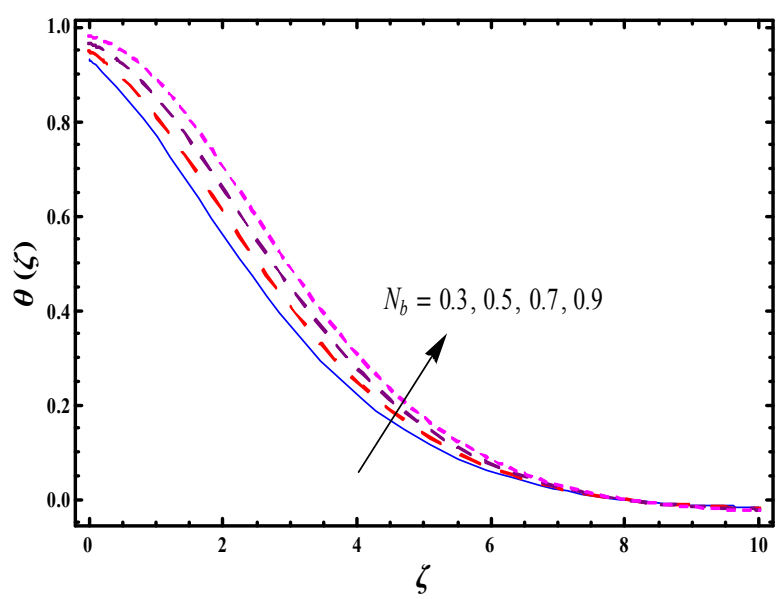

Figure 11. Sketch of $\theta(\zeta)$ for $N_{b}$.

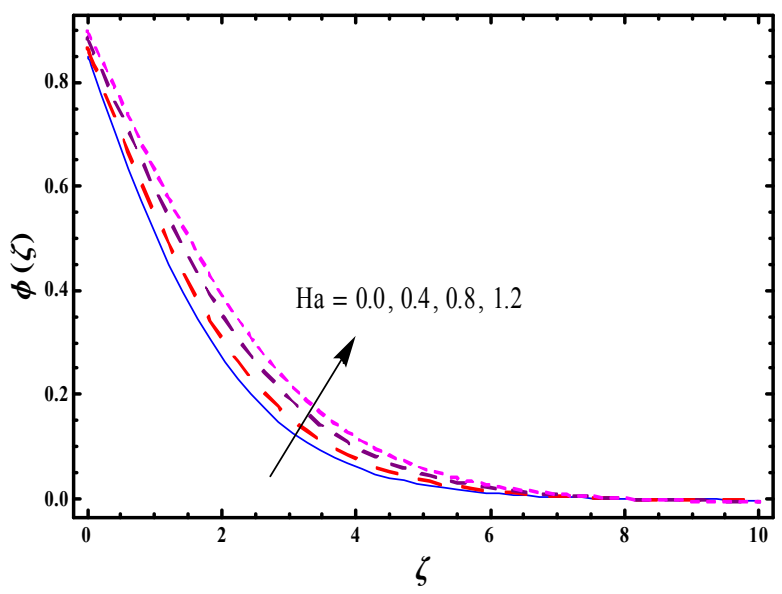

Figure 12. Sketch of $\phi(\zeta)$ for $H a$. 


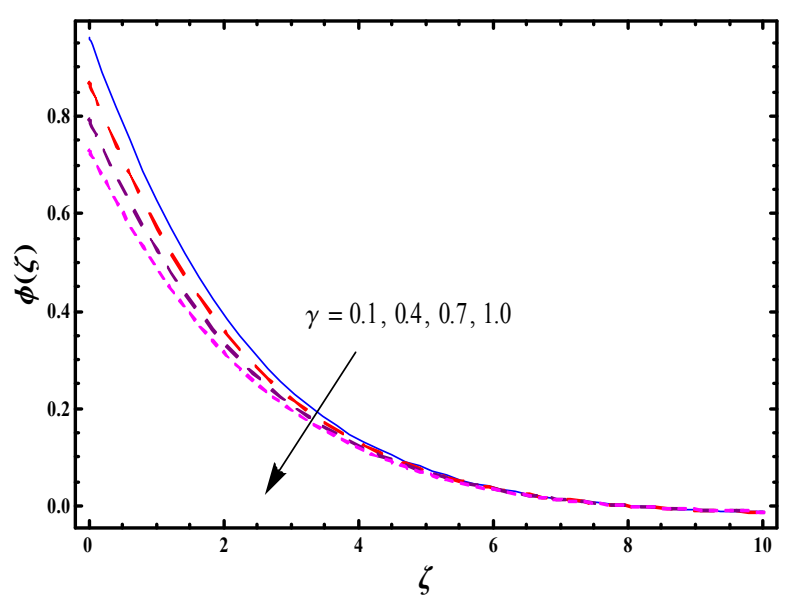

Figure 13. Sketch of $\phi(\zeta)$ for $\gamma$.

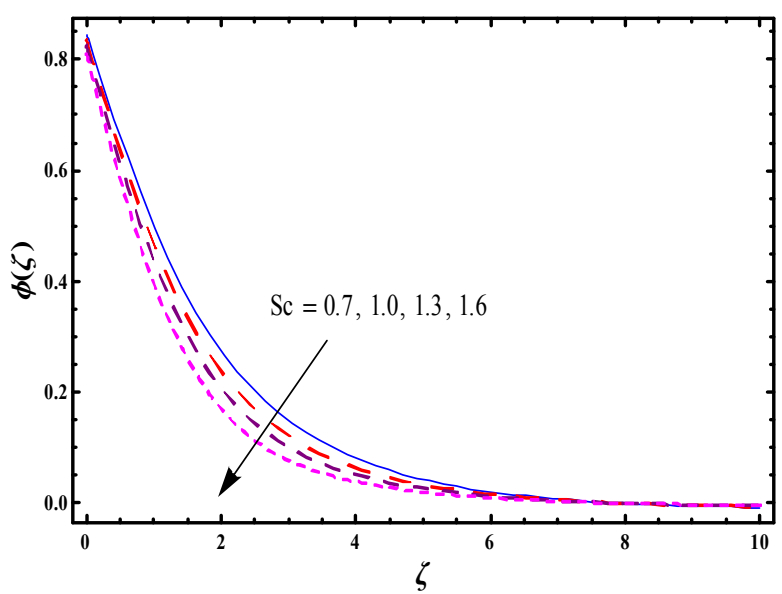

Figure 14. Sketch of $\phi(\zeta)$ for $S c$.

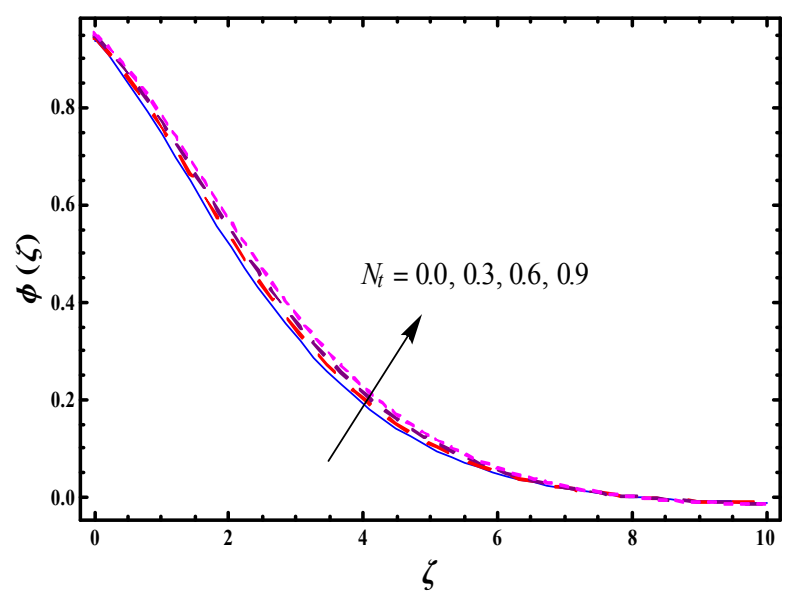

Figure 15. Sketch of $\phi(\zeta)$ for $N_{t}$. 


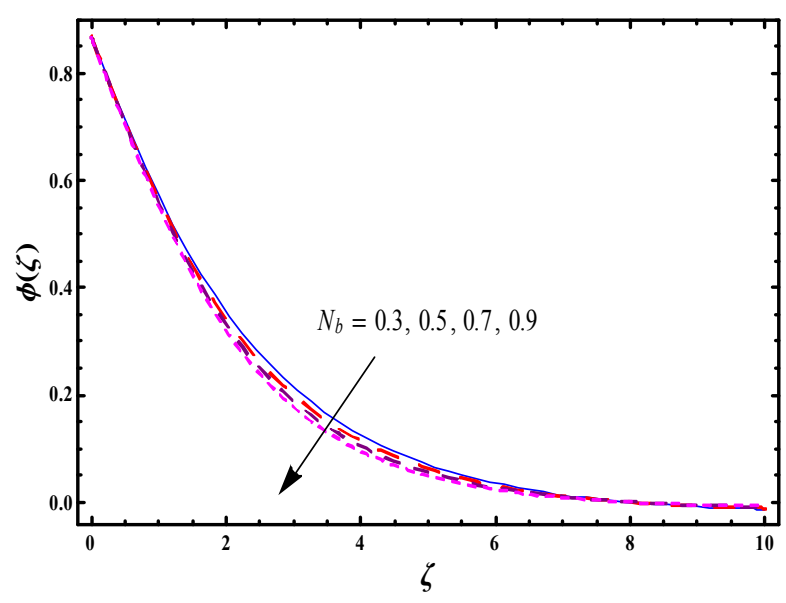

Figure 16. Sketch of $\phi(\zeta)$ for $N_{b}$.

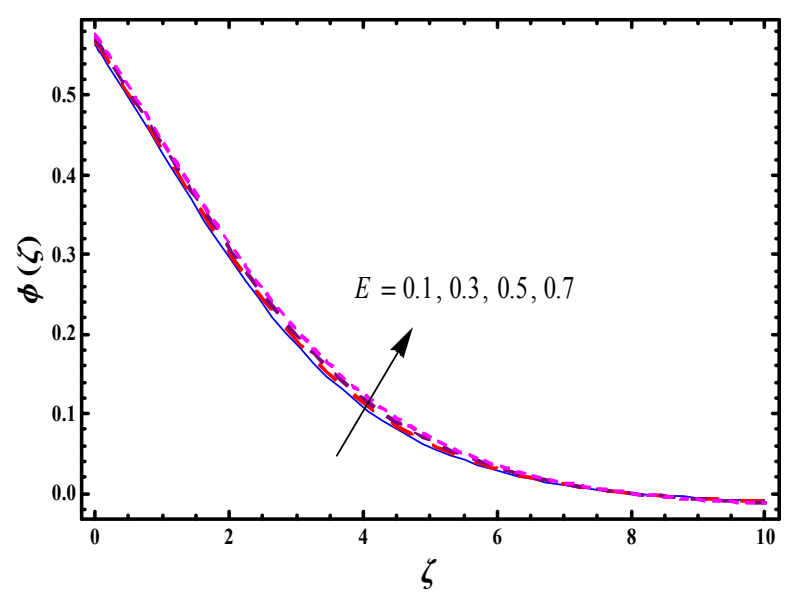

Figure 17. Sketch of $\phi(\zeta)$ for $E$.

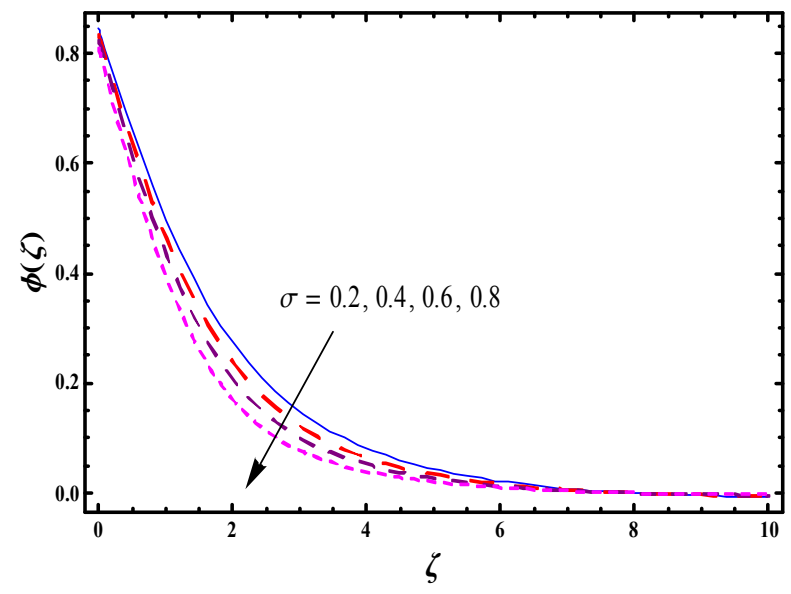

Figure 18. Sketch of $\phi(\zeta)$ for $\sigma$. 


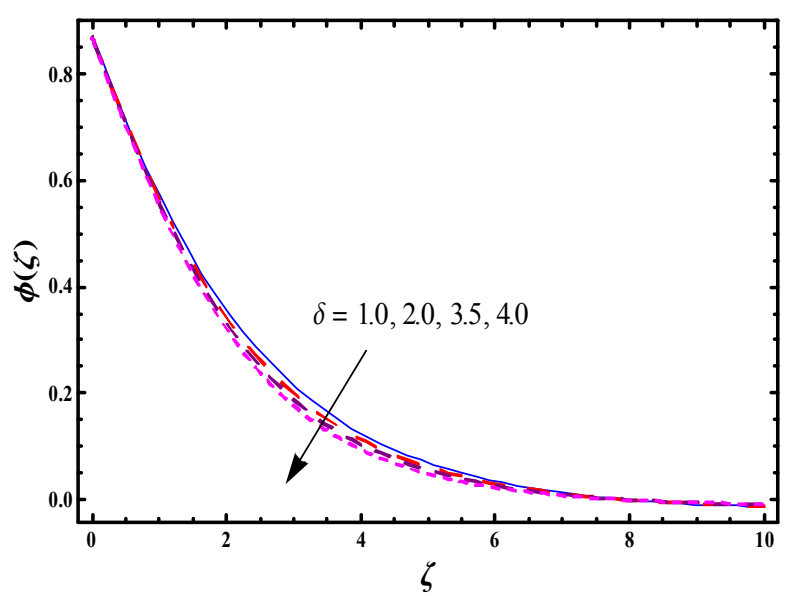

Figure 19. Sketch of $\phi(\zeta)$ for $\delta$.

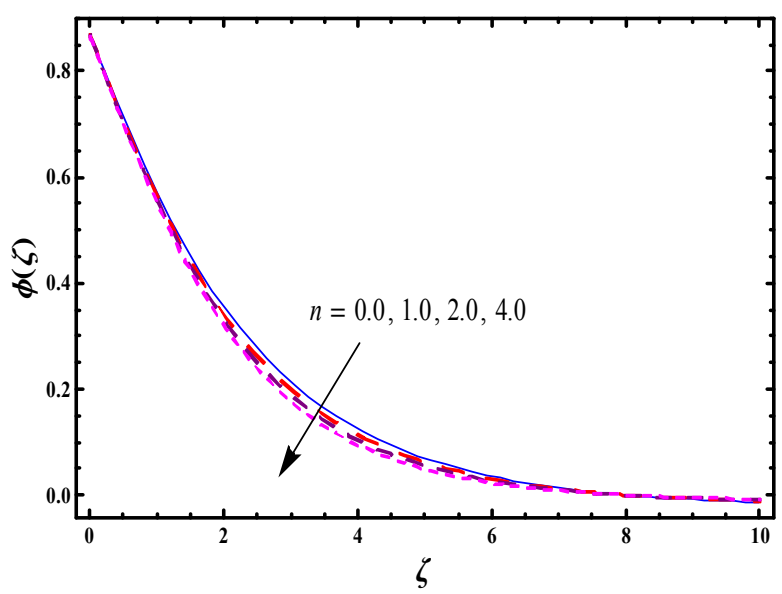

Figure 20. Sketch of $\phi(\zeta)$ for $n$.

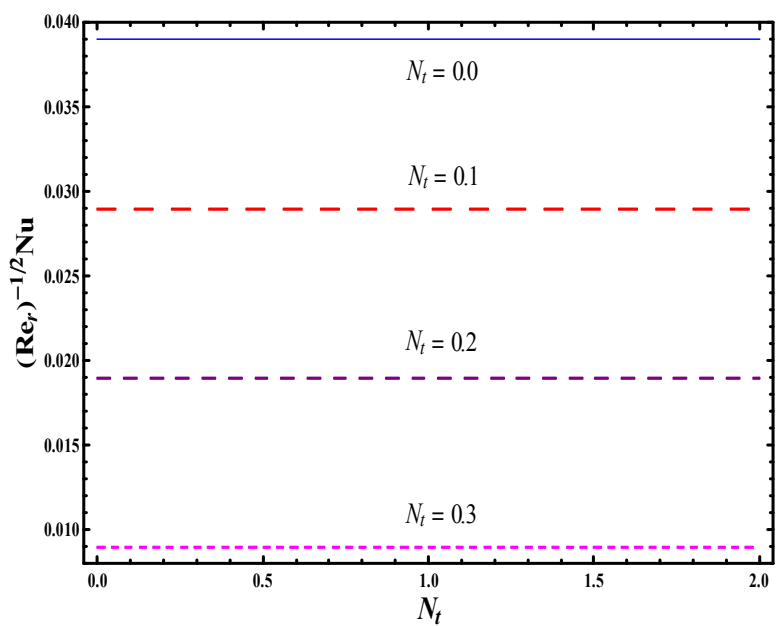

Figure 21. Sketch of $\operatorname{Re}_{r}^{-1 / 2} N u$ for $N_{t}$. 


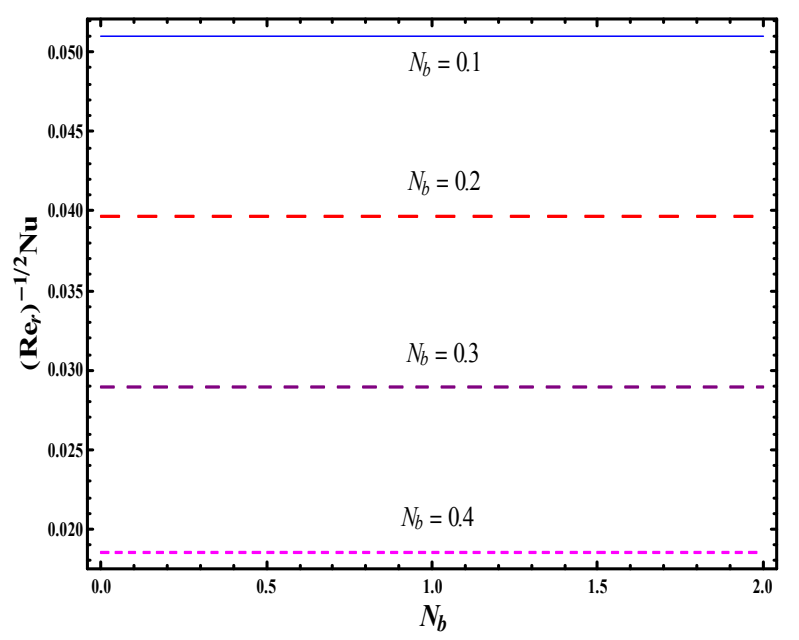

Figure 22. Sketch of $\operatorname{Re}_{r}^{-1 / 2} N u$ for $N_{b}$.

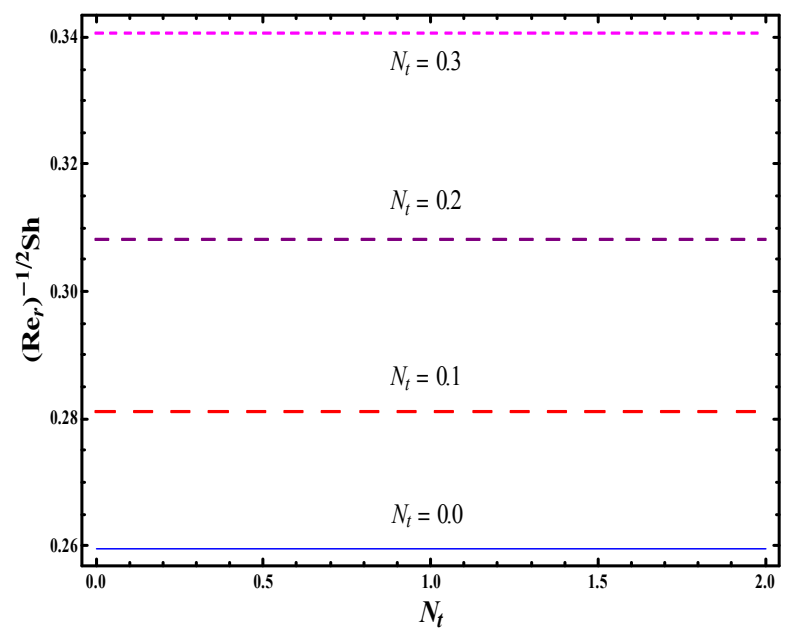

Figure 23. Sketch of $\operatorname{Re}_{r}^{-1 / 2} S h$ for $N_{t}$.

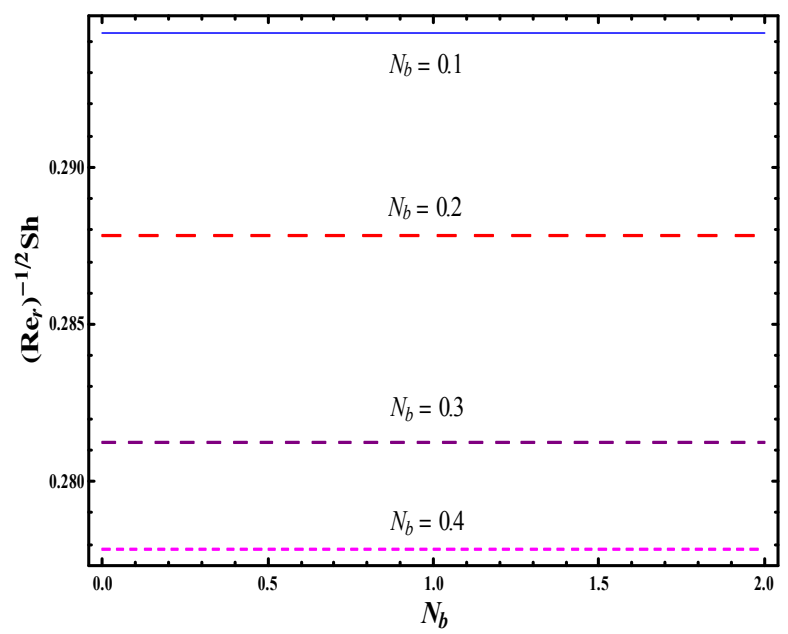

Figure 24. Sketch of $\operatorname{Re}_{r}^{-1 / 2} S h$ for $N_{b}$. 


\section{Conclusions}

Magnetohydrodynamic viscous nanoliquid 3D flow by rotating disk with heat absorption/generation, binary chemical reaction and Arrhenius activation energy is examined. Major results are given as follows:

- Larger velocity slip $\alpha$ and Hartman number $H a$ show decreasing trend for both velocities $f^{\prime}(\zeta)$ and $g(\zeta)$.

- Both concentration and temperature depict increasing trend for increasing $\mathrm{Ha}$.

- Higher Pr corresponds to weaker temperature while the reverse behavior is seen for $\delta_{1}$.

- $\quad$ Stronger temperature distribution is seen for $N_{b}$ and $N_{t}$.

- Higher $\gamma$ exhibits a decreasing trend for the concentration field.

- Higher activation energy $E$ shows stronger concentration $\phi(\zeta)$.

- Concentration $\phi(\zeta)$ depicts decreasing behavior for larger $\delta$ and $\sigma$.

- Both concentration $\phi(\zeta)$ is a decreasing factor of higher $S c$.

- Concentration $\phi(\zeta)$ displays reverse behavior for $N_{b}$ and $N_{t}$.

Author Contributions: All the authors have contributed equally to this manuscript.

Funding: This project was funded by the Deanship of Scientific Research (DSR), King Abdulaziz University, Jeddah, Saudi Arabia under grant no. (KEP-16-130-40).

Acknowledgments: This project was funded by the Deanship of Scientific Research (DSR), King Abdulaziz University, Jeddah, Saudi Arabia under grant no. (KEP-16-130-40). The authors, therefore, acknowledge with thanks DSR technical and financial support.

Conflicts of Interest: The authors declare no conflict of interest.

\section{References}

1. Hsiao, K.L. Nanofluid flow with multimedia physical features for conjugate mixed convection and radiation. Comput. Fluids 2014, 104, 1-8. [CrossRef]

2. Wen, B.; Corson, L.T.; Chini, G.P. Structure and stability of steady porous medium convection at large Rayleigh number. J. Fluid Mech. 2015, 772, 197-224. [CrossRef]

3. Hsiao, K.L. Stagnation electrical MHD nanofluid mixed convection with slip boundary on a stretching sheet. Appl. Therm. Eng. 2016, 98, 850-861. [CrossRef]

4. Hsiao, K.L. Micropolar nanofluid flow with MHD and viscous dissipation effects towards a stretching sheet with multimedia feature. Int. J. Heat Mass Transf. 2017, 112, 983-990. [CrossRef]

5. Wen, B.; Chang, K.W.; Hesse, M.A. Rayleigh-Darcy convection with hydrodynamic dispersion. Phys. Rev. Fluids 2018, 3, 123801. [CrossRef]

6. Choi, S.U.S. Enhancing thermal conductivity of fluids with nanoparticles. In Proceedings of the ASME International Mechanical Engineering Congress \& Exposition, San Francisco, CA, USA, 12-17 November 1995; Volume 66, pp. 99-105.

7. Eastman, J.A.; Choi, S.U.S.; Li, S.; Yu, W.; Thompson, L.J. Anomalously increased effective thermal conductivities of ethylene glycol-based nanofluids containing copper nanoparticles. Appl. Phys. Lett. 2001, 78, 718-720. [CrossRef]

8. Buongiorno, J. Convective transport in nanofluids. J. Heat Transf. 2006, 128, 240-250. [CrossRef]

9. Tiwari, R.K.; Das, M.K. Heat transfer augmentation in a two-sided lid-driven differentially heated square cavity utilizing nanofluid. Int. J. Heat Mass Transf. 2007, 50, 2002-2018. [CrossRef]

10. Abu-Nada, E.; Oztop, H.F. Effects of inclination angle on natural convection in enclosures filled with Cu-water nanofluid. Int. J. Heat Fluid Flow 2009, 30, 669-678. [CrossRef]

11. Khan, J.A.; Mustafa, M.; Hayat, T.; Farooq, M.A.; Alsaedi, A.; Liao, S.J. On model for three-dimensional flow of nanofluid: An application to solar energy. J. Mol. Liq. 2014, 194, 41-47. [CrossRef]

12. Mansur, S.; Ishak, A. Three-dimensional flow and heat transfer of a nanofluid past a permeable stretching sheet with a convective boundary condition. AIP Conf. Proc. 2014, 1614, 906.

13. Hayat, T.; Muhammad, T.; Alsaedi, A.; Alhuthali, M.S. Magnetohydrodynamic three-dimensional flow of viscoelastic nanofluid in the presence of nonlinear thermal radiation. J. Magn. Magn. Mater. 2015, 385, 222-229. [CrossRef] 
14. Hayat, T.; Aziz, A.; Muhammad, T.; Alsaedi, A. On magnetohydrodynamic three-dimensional flow of nanofluid over a convectively heated nonlinear stretching surface. Int. J. Heat Mass Transf. 2016, 100, 566-572. [CrossRef]

15. Muhammad, T.; Alsaedi, A.; Hayat, T.; Shehzad, S.A. A revised model for Darcy-Forchheimer threedimensional flow of nanofluid subject to convective boundary condition. Results Phys. 2017, 7, 2791-2797. [CrossRef]

16. Hayat, T.; Muhammad, T.; Shehzad, S.A.; Alsaedi, A. An analytical solution for magnetohydrodynamic Oldroyd-B nanofluid flow induced by a stretching sheet with heat generation/absorption. Int. J. Therm. Sci. 2017, 111, 274-288. [CrossRef]

17. Muhammad, T.; Alsaedi, A.; Shehzad, S.A.; Hayat, T. A revised model for Darcy-Forchheimer flow of Maxwell nanofluid subject to convective boundary condition. Chin. J. Phys. 2017, 55, 963-976. [CrossRef]

18. Selimefendigil, F.; Oztop, H.F. Mixed convection of nanofluids in a three dimensional cavity with two adiabatic inner rotating cylinders. Int. J. Heat Mass Transf. 2018, 117, 331-343. [CrossRef]

19. Sheikholeslami, M.; Hayat, T.; Muhammad, T.; Alsaedi, A. MHD forced convection flow of nanofluid in a porous cavity with hot elliptic obstacle by means of Lattice Boltzmann method. Int. J. Mech. Sci. 2018, 135, 532-540. [CrossRef]

20. Mahanthesh, B.; Gireesha, B.J.; Animasaun, I.L.; Shashikumar, T.M.a.S. MHD flow of SWCNT and MWCNT nanoliquids past a rotating stretchable disk with thermal and exponential space dependent heat source. Phys. Scr. 2019, 94, 085214. [CrossRef]

21. Hu, Z.; Lu, W.; Thouless, M.D. Slip and wear at a corner with Coulomb friction and an interfacial strength. Wear 2015, 338, 242-251. [CrossRef]

22. Hu, Z.; Lu, W.; Thouless, M.D.; Barber, J.R. Effect of plastic deformation on the evolution of wear and local stress fields in fretting. Int. J. Solids Struct. 2016, 82, 1-8. [CrossRef]

23. Wang, H.; Hu, Z.; Lu, W.; Thouless, M.D. The effect of coupled wear and creep during grid-to-rod fretting. Nucl. Eng. Des. 2017, 318, 163-173. [CrossRef]

24. von Karman, T. Uberlaminare und turbulente Reibung. Z. Angew. Math. Mech. ZAMM 1921, 1, $233-252$. [CrossRef]

25. Cochran, W.G. The flow due to a rotating disk. Math. Proc. Camb. Philos. Soc. 1934, 30, 365-375. [CrossRef]

26. Millsaps, K.; Pohlhausen, K. Heat transfer by laminar flow from a rotating disk. J. Aeronaut. Sci. 1952, 19, 120-126. [CrossRef]

27. Ackroyd, J.A.D. On the steady flow produced by a rotating disk with either surface suction or injection. J. Eng. Math. 1978, 12, 207-220. [CrossRef]

28. Miclavcic, M.; Wang, C.Y. The flow due to a rough rotating disk. Z. Angew. Math. Phys. 2004, 54, 1-12. [CrossRef]

29. Attia, H.A. Steady flow over a rotating disk in porous medium with heat transfer. Nonlinear Anal.-Model. Control 2009, 14, 21-26

30. Turkyilmazoglu, M.; Senel, P. Heat and mass transfer of the flow due to a rotating rough and porous disk. Int. J. Therm. Sci. 2013, 63, 146-158. [CrossRef]

31. Rashidi, M.M.; Kavyani, N.; Abelman, S. Investigation of entropy generation in MHD and slip flow over a rotating porous disk with variable properties. Int. J. Heat Mass Transf. 2014, 70, 892-917. [CrossRef]

32. Hatami, M.; Sheikholeslami, M.; Ganji, D.D. Laminar flow and heat transfer of nanofluid between contracting and rotating disks by least square method. Powder Technol. 2014, 253, 769-779. [CrossRef]

33. Mustafa, M.; Khan, J.A.; Hayat, T.; Alsaedi, A. On Bodewadt flow and heat transfer of nanofluids over a stretching stationary disk. J. Mol. Liq. 2015, 211, 119-125. [CrossRef]

34. Sheikholeslami, M.; Hatami, M.; Ganji, D.D. Numerical investigation of nanofluid spraying on an inclined rotating disk for cooling process. J. Mol. Liq. 2015, 211, 577-583. [CrossRef]

35. Hayat, T.; Muhammad, T.; Shehzad, S.A.; Alsaedi, A. On magnetohydrodynamic flow of nanofluid due to a rotating disk with slip effect: A numerical study. Comput. Methods Appl. Mech. Eng. 2017, 315, 467-477. [CrossRef]

36. Mustafa, M. MHD nanofluid flow over a rotating disk with partial slip effects: Buongiorno model. Int. J. Heat Mass Transf. 2017, 108, 1910-1916. [CrossRef]

37. Hayat, T.; Haider, F.; Muhammad, T.; Alsaedi, A. On Darcy-Forchheimer flow of carbon nanotubes due to a rotating disk. Int. J. Heat Mass Transf. 2017, 112, 248-254. [CrossRef] 
38. Pop, I.; Soundalgekar, V.M. The Hall effect on an unsteady flow due to a rotating infinite disc. Nucl. Eng. Des. 1977, 44, 309-314. [CrossRef]

39. Bachok, N.; Ishak, A.; Pop, I. Flow and heat transfer over a rotating porous disk in a nanofluid. Phys. B Condens. Matter 2011, 406, 1767-1772. [CrossRef]

40. Lok, Y.Y.; Merkin, J.H.; Pop, I. Axisymmetric rotational stagnation-point flow impinging on a permeable stretching/shrinking rotating disk. Eur. J. Mech. B/Fluids 2018, 72, 275-292. [CrossRef]

(C) 2019 by the authors. Licensee MDPI, Basel, Switzerland. This article is an open access article distributed under the terms and conditions of the Creative Commons Attribution (CC BY) license (http:/ / creativecommons.org/licenses/by/4.0/). 